\title{
PARA QUE "CRECIERA El PUEBLO COMO POTOSÍ": LA MINERÍA EN LA PUNA DE JUJUY DURANTE EL PERÍODO COLONIAL
}

\author{
María Florencia Becerra ${ }^{1}$
}

\section{* Introducción}

Resumen

Este artículo tiene como objetivo dar cuenta de las características que adquirió la minería en la puna de Jujuy durante el período colonial. A lo largo de este trabajo se sintetizan los resultados alcanzados, atendiendo a la constitución de la región como un área minera, a la escala de trabajo e inversión de los emprendimientos desarrollados allí y a quienes se involucraron de distinta forma en ellos. Se observa así que

la actividad extractiva a baja y mediana escala, llevada adelante por europeos e indígenas, adquirió un rol muy importante en la dinámica socio-política de la puna. Finalmente, se reflexiona sobre los procesos observados en esta región en comparación con el resto de la macroregión conformada por el Tucumán colonial.

Palabras claves: minería - puna de Jujuy - período Colonial.

Abstract

This paper aims to describe the characteristics of mining activities in the Puna of Jujuy acquired during colonial times. In this article we summarize the results of our research, taking into account the constitution of this region as a mining area, the scale of work and investment of the enterprises developed there and the people involved in these activities. It is observed that the low and medium scale extractive labours carried out by European and Indigenous people played an important role in the socio-political dynamics of the Puna region. Finally, we consider the processes observed in this area, comparing them with the rest of the macro-region of the colonial Tucumán.

Key words: mining - puna of Jujuy - Colonial period.

Recibido: julio 2014. Aceptado: octubre 2014.
El inicio de la actividad minera a gran escala a partir de la conquista española generó una serie de profundos cambios en las sociedades americanas y en los territorios invadidos. Además de significar la expropiación de una enorme cantidad de recursos minerales hacia la metrópoli y, de allí, al resto de Europa, la minería fue motor de ocupación y de nuevas estructuraciones sociopolíticas y económicas del espacio (Assadourian 1982; Tandeter 1992) como también de movilización de personas en los Andes durante la colonia (Cole 1985; Saignes 1987; Bakewell 1989; Tandeter 1992; Gil Montero 2011). En este sentido ha sido señalada frecuentemente como un factor de desestructuración y exterminio de las poblaciones indígenas, forzadas a la explotación de los yacimientos de plata y oro "descubiertos" en las regiones conquistadas (Sánchez Albornoz 1978). Sumado a ello, la explotación minera también representó la conquista de los cerros sagrados o wak'as que tanta relevancia tuvieron para las poblaciones andinas (Salazar-Soler 1997; Bouysse-Cassagne 2005, Platt et al. 2006).

Por la escala de los trabajos desarrollados y el impacto de su explotación, el área de Porco-Potosí ha acaparado la mayor parte de los estudios sobre minería en la región andina (Bakewell 1989; Tandeter 1992; Salazar-Soler 2002; Téreygeol y Castro 2008; Van Buren y Cohen 2010; entre muchos otros). Por el contrario, son más escasos los estudios de otros centros que no lograron alcanzar los niveles de producción ni predominancia de aquélla, aunque adquirieran cierta relevancia regional. Los trabajos de

\footnotetext{
1 Instituto Superior de Estudios Sociales (ISES - IAM), Consejo Nacional de Investigaciones Científicas y Técnicas (CONICET). San Martín 1545, San Miguel de Tucumán (4000), Argentina. Email: florenciabecerra@gmail.com
} 
Gavira $(2005,2008)$ sobre Oruro, Carangas y el mineral de Huantajaya; el estudio de Cuadra y Arenas (2001) en la región aurífera del norte de Chile; los estudios arqueológicos e históricos de Cruz et al. (2012) y de Cruz (2013), así como los de Gil Montero (2012) en San Antonio del Nuevo Mundo en Lípez; y las investigaciones llevadas adelante en Incahuasi, Catamarca (Haber y Lema 2006; Lema 2012) o en los valles Calchaquíes (González 1999; Gluzman 2007) son algunos ejemplos de ello y demuestran la importancia de analizar las "otras minerías" por fuera de la potosina (González Casasnovas 2000: 189).

En esta línea, el caso de la llamada puna de Jujuy, en el extremo sur del altiplano andino, dentro de los límites de la actual Argentina, resulta sumamente interesante para ser estudiado en profundidad. Una de sus particularidades la constituye el hecho de que es una región reconocida por ser rica en minerales de oro y plata, cuyo pasado colonial y reciente se encuentra íntimamente vinculado a la minería, a pesar de que esta actividad no alcanzara la magnitud observada en otros centros extractivos contemporáneos de los Andes. En este sentido, nos encontramos frente a un desarrollo minero a mediana y baja escala, considerablemente periférico a dichos polos mineros, aunque íntimamente vinculado a ellos, el que más allá de esto, se habría distinguido del resto de las regiones del Tucumán colonial por su condición de área minera. A lo largo de este artículo pretendemos adentrarnos en estas cuestiones, dando cuenta de las características que la minería puneña adquirió durante el período colonial y del papel jugado por la misma en la dinámica socio-política de dicha región.

\section{* ¿LAa puna de Jujuy como región minera?}

La llamada puna de Jujuy, que comprende los actuales departamentos jujeños de Yavi, Santa Catalina, Cochinoca y gran parte del de Rinconada, presenta numerosos yacimientos de minerales metaliferos. Son especialmente reconocidas las manifestaciones de oro en veta y aluviones a lo largo de la sierra de la Rinconada y su prolongación septentrional, y las importantes minas de plomo, plata y zinc en la zona de Pan de Azúcar, Chinchillas (fundiciones), Rachaite y La Candelaria (Coira et al. 2004). La presencia de estos recursos en la región no habría pasado inadvertida a los conquistadores europeos, quienes ya desde finales del siglo XVI se habrían instalado allí en pos de explotarlos.
En efecto, diversas investigaciones han señalado cómo a lo largo de todo el período colonial las ansias de riquezas y las posibilidades de obtenerlas a partir de las explotaciones en la región, convirtieron a la puna de Jujuy en un hábitat ocupado tanto por europeos como por indígenas, generando asentamientos de distintas características y escalas y también conflictos en torno al control de esos recursos minerales (p.e. Gil Montero 2004; Sica 2006; Palomeque 2006; Estruch 2013). En este contexto, los mineros de cualquier origen mostraron desde los primeros años un excelente conocimiento del terreno, tomando como puntos de referencia en sus solicitudes y demandas tanto a los asientos de mineral recientemente fundados como a poblados antiguos prehispánicos (ABNB, Minas 62-4, año 1657; Becerra y Estruch 2011, 2012; Becerra 2012).

Como hemos mencionado, lo particular de la puna de Jujuy es que más allá de las explotaciones registradas arqueológica y documentalmente, su economía regional no se basó de modo principal en la minería local. Más bien fue el auge de los centros mineros septentrionales de Charcas, los que con sus demandas movilizaron la producción puneña, principalmente ganadera (Conti 2010) ${ }^{2}$. A pesar de ello, la actividad extractiva en la región, a baja escala y en áreas limitadas, jugó un rol muy importante en la configuración y organización de todo este territorio, a la par de los procesos de cesiones de mercedes de tierra y encomienda, y de establecimiento de circuitos mercantiles (Albeck y Palomeque 2009). En este sentido, la presencia de yacimientos en determinados sectores de la región colaboró en que fueran ésos y no otros los primeros espacios conocidos y poblados por los conquistadores, ejerciendo así una selectividad espacial (Corrêa 1995). Se observa así, que la valorización de las distintas áreas mineras en la puna varió durante el período estudiado, a la par de los nuevos descubrimientos y de los vaivenes de la producción minera, provocando la marginalización de determinados sectores y el auge de otros (Becerra 2012).

\footnotetext{
2 Dentro del espacio económico peruano analizado por Assadourian (1982) la región puneña se destacó principalmente por su producción ganadera (exportación de ganados a las minas altoperuanas y de lanas de vicuñas y guanacos hacia el puerto de Buenos Aires) y de los bienes derivados de esta actividad (carne, cueros, lana, quesos), como también de las manufacturas de tejidos, pieles y alfarería, que en ciertas zonas de clima más favorable, se complementaba con agricultura bajo riego (alfalfa, cebada, habas y frutales) (ver Palomeque 2000; Conti 2010).
} 
Uno de los puntos interesantes del caso es que estas explotaciones permitieron diferenciar desde los primeros momentos a este territorio del resto de las regiones conformadas por la jurisdicción jujeña. La puna se constituyó así en un "espacio minero" con exigencias de autoridades específicas a esta actividad y privilegios propios a los "minerales" reconocidos en el área andina. Esta consolidación como área minera no estuvo, sin embargo, exenta de conflictos. Por ejemplo, durante el pleito desatado a finales del siglo XVII entre los capitulares jujeños y el encomendero local, el marqués del Valle de Tojo Juan José Campero de Herrera, junto al entonces Teniente de Gobernador y Justicia Mayor, Miguel Bernárdez de Ovando, la minería y su relevancia en la región se encontró en el foco de las argumentaciones (Estruch 2013). En esa oportunidad, esta actividad fue esgrimida explícitamente por Campero como una de las razones fundamentales de la necesidad de una autoridad local propia, con sede en el asiento de Rinconada, nombrada por el gobernador del Tucumán. En sus palabras, la zona se componía "de algunos minerales” (ABNB, Minas 62-7, años 1692-1712, f. $8 \mathrm{v}$ ) y requería, por tanto, de quien pudiera resolver las cuestiones mineras sin dilación, cobrar los quintos reales y recibir los registros. Las autoridades de la ciudad de San Salvador de Jujuy a muchas leguas de distancia no podrían hacerlo a tiempo, como tampoco cuidarían de los viajantes y comerciantes que continuamente pasaban por esta "garganta para el paso del comercio del Perú y del Tucumán, Lípez y Tarija" (ABNB, Minas 62-7, años 1692-1712, f. 7v; Becerra y Estruch 2012). Por su parte, el cabildo jujeño afirmaba que ya no existían minerales en la región, que la distancia no conformaba una barrera y que los alcaldes de la ciudad podían hacerse cargo de estos asuntos sin inconveniente alguno (ABNB, Minas 62-7, años 1692-1712; Estruch 2013). En realidad, lo que estaba en juego, más que una real preocupación por facilitar el desarrollo de la minería en la región -que en efecto, pareciera haber decaído en ese período - era el control de este territorio y especialmente de su población mediante la "mita de plaza", como también, en el caso de los

3 El cabildo de Jujuy reclamaba la sexta parte de los indios de la encomienda de Casabindo y Cochinoca para que brindara servicio a la mita de plaza de la ciudad, a lo que Campero respondía que no era conveniente por las diferencias de temple entre ambas regiones (Madrazo 1982; Estruch et al. 2011; Estruch 2013). Recientemente Sica (2014) ha tratado con detalle la cuestión de la mita de plaza en Jujuy. jujeños, el impedir que se consolidara un foco de poder independiente entre el encomendero y esta "doble" autoridad, desplazando completamente al cabildo (Estruch et al. 2011; Estruch 2013).

Finalizado este pleito, los tenientes de la puna dejaron de ser nombrados por el gobernador y de tener sede en la región, dependiendo el ejercicio de la justicia puneña completamente de las autoridades de San Salvador de Jujuy. Sin embargo, en el último tercio del siglo XVIII, con los cambios introducidos por las reformas Borbónicas, se designó una nueva figura de autoridad con sede en la puna, el Subdelegado del Partido. La actividad minera en el área también habría tenido relación con su nombramiento, ya que su título incluiría el de Alcalde de Minas. Éste, tal como su antecesor, comenzó a generar malestar en los capitulares jujeños que perderían autoridad en la región ${ }^{4}$. En el conflicto desatado por la supuesta mala gestión de uno de los subdelegados, entre los años 1782 y 1795, los argumentos de ambas partes fueron muy semejantes a aquéllos planteados un siglo antes por el marqués y el cabildo, especialmente en relación a la riqueza mineral de la puna y a la distancia entre esta región y San Salvador de Jujuy (AGN, Sala IX, 33-8-5, año 1793, fs. 35, 79v, 93v).

Años después, en 1803, quien se encontraba ejerciendo el cargo de subdelegado también se vio envuelto en un pleito con los propietarios de la hacienda de la Rinconada en ese momento, Ángel Antonio de la Barcena y sucesores (Gil Montero 2004). El caballo de batalla en esta lucha fue esta vez, el carácter o no de "asiento" de mineral de la Rinconada, y por tanto, los privilegios que esto conllevaba. Para el subdelegado y los arrendatarios de la hacienda, el cobro de arriendos y la exigencia de pago de derechos de matanzas eran no sólo perjudiciales sino contra las ordenanzas "por el lugar que ocupa en el mineral de la Rinconada" (AGN, Sala IX, 5-8-1, años 1784-1809, f. 1). Declaraban así que "en los inmediatos asientos de minerales de Santa Catalina, Antiguyo, Portugalete y otros" no exigían "los dueños de aquellos terrenos absolutamente reconocimiento ni obligaciones a los mineros y abastecedores" (AGN, Sala IX, 23-5-6,

4 De hecho, fue la creación de la Intendencia de Salta en sí misma un ataque a la autonomía de Jujuy a medida que la ciudad de Salta concentraba, como capital, un gran poder en desmedro de los intereses jujeños (Paz 2004). 
Exp. 310, año 1803, fs. 4V y 84). Por el contrario, para los Barcena el conflicto radicaba en "una ordenanza de minas mal entendida" y en que este asiento no era "mineral que con propiedad se llama sólo en el que se laborea veta fija. En la Rinconada no hay más que lavaderos y aventaderos cuya economía de trabajo no exige las formalidades de minas en vetas fijas" (AGN, Sala IX, 23-5-6, Exp. 314, año 1803 , fs. $7 v$ y 40 ). Subestimando a la minería local y desligando el cargo de la regulación de esta actividad, para el hacendado, el subdelegado debía administrar justicia en otros asientos de la zona, como Santa Catalina, Casabindo o Cochinoca. Más allá de las argumentaciones de cada uno, en esta oportunidad lo que verdaderamente se ponía en juego habría sido la posibilidad de "abarcar el comercio y rescate de oro" extraído en la región (AGN, Sala IX, 23-5-6, Exp. 312, año 1803, f. 56).

Así como se exigía la exención de los cobros de arriendos por las características del asiento, también se registra en la documentación de este período el rechazo de los pulperos de los pueblos de la región a pagar el derecho de composición porque "alegan en su favor que este es un asiento de minerales en que deben expenderse los víveres sin pensión alguna" (ABHS, Fondos de Gobierno, Carpeta 14A, año 1793, f. 1v). Ante estas solicitudes y conflictos de larga duración, no cabe más que preguntarnos acerca de las características que efectivamente adquirió el desarrollo minero de la región y su verdadero peso en la dinámica de la misma. En el siguiente apartado nos referiremos a esta cuestión en detalle.

\section{* Las prácticas minero-metalúrgicas en la PUNA DE JUJUY}

La documentación colonial referente a las actividades minero-metalúrgicas en la puna de Jujuy no es numerosa y en la mayoría de los casos no ofrece detalladas descripciones acerca de las instalaciones de trabajo, la escala de las labores y los operarios involucrados. Sin embargo, el análisis crítico de las mismas en conjunto con las investigaciones históricas previas (Palomeque 1994, 2006; Gil Montero 2004; Sica 2006; Albeck y Palomeque 2009) y los estudios arqueológicos desarrollados allí en los últimos diez años (Angiorama 2011; Angiorama y Becerra 2010, 2012; Becerra 2009; 2014) nos han permitido avanzar sobre estas problemáticas.
Por un lado, como hemos adelantado, observamos en los registros escritos de todo el período colonial una aparente contradicción entre la dimensión de las labores y procesamiento de minerales referidas, y el rol adquirido por la actividad en la dinámica socio-política regional. Por ejemplo, en tanto se afirmaba a inicios del siglo XVII que las minas de la puna resultaban prometedoras y reunían a distintos emprendedores por su gran riqueza, unos años después un minero declaraba que no se habían "fundado moliendas por no haber comodidad para ello más de los marays ${ }^{5}$ que han hecho" (ABNB, Minas 62-3, año 1646, f. 24), y a finales del siglo XVIII, las autoridades de la Intendencia de Salta del Tucumán aludían al "ningún método que se observa en los minerales de aquellos pueblos, para el trabajo de sus minas, así de plata, como de oro" (AGN, 33-8-5, año 1784, f.5v). Aunque estas afirmaciones tenían en parte sustento ya que "como aquel oro se halla en pepitas no tiene más beneficio que el separarlo de la tierra mediante el agua por eso no tienen oficinas ni más ingenios o máquinas que algunos simples transportables instrumentos para remover la tierra" (AGN, Sala IX, 362-5, año 1802, f. 11).

Lo cierto es que en documentación contemporánea a estos escritos se pueden observar inversiones considerables para la edificación de instalaciones donde procesar minerales de plata y oro explotados en la región e inmediaciones. Nos referimos a los ingenios de San Isidro de Madrid, del Valle Rico y de San Joseph construidos en la región en la primera mitad del siglo XVII, y a los emprendimientos desarrollados por los mineros Barcena, Baldivieso y Tames a finales del XVIII (ABNB, Minas 62-3, año 1646; ABNB, Minas 62-4, año 1657; ABNB, EC 25, año 1674; ATJ, Carpeta 5 , Leg. 86, año 1629; ATJ, Carpeta 59, Leg. 1914, año 1789; AGN, Sala IX, 36-2-5, año 1802); Albeck y Palomeque 2009; Becerra 2009; Becerra y Estruch 2012). De hecho, como hemos desarrollado en el apartado anterior, eran diversos los intereses involucrados a la hora de mencionar el efectivo éxito o fracaso de las explotaciones mineras, ya que lo que se encontraba en juego era la justificación de determinados ordenamientos de jurisdicciones y autoridades de la región de acuerdo al reconocimiento o no de la importancia de la actividad minera desarrollada.

\footnotetext{
5 Se denomina maray a un instrumento de molienda conformado por una gran roca de forma tronco-piramidal, movida por balanceo o rotación sobre otra roca plana.
} 


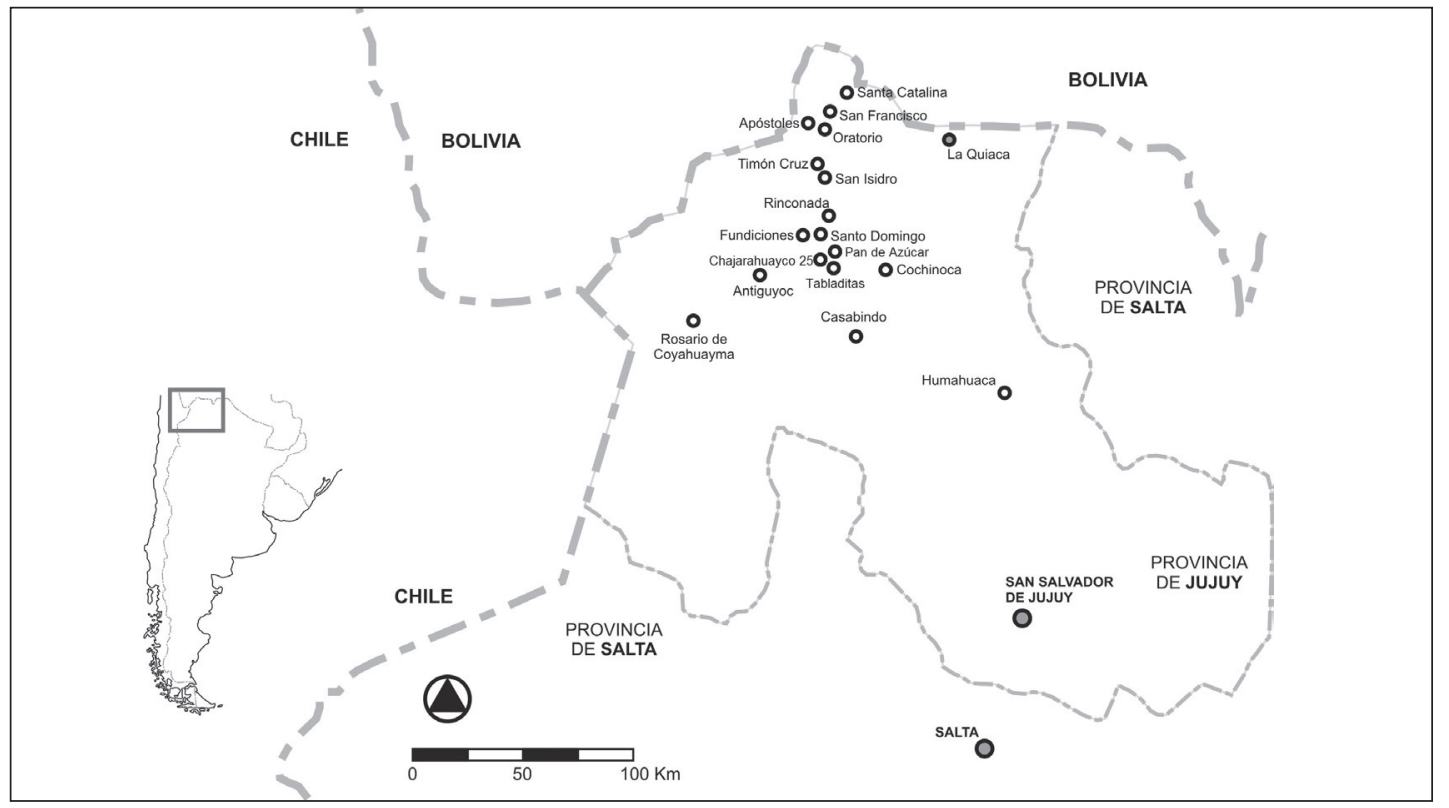

Figura 1: Mapa de ubicación aproximada de los asientos de mineral e instalaciones minero-metalúrgicas más relevantes de la Puna de Jujuy mencionados en este trabajo. Al sur de Santa Catalina se ubican los sitios de la cuenca del río homónimo, mientras que al sur de Rinconada están los de la cuenca sur de Pozuelos e inmediaciones (mapa base confeccionado por Jorge Tomasi y modificado por la autora).

Más allá de estas disputas, lo que puede observarse a partir de las investigaciones arqueológicas e históricas, es que la minería del oro, aún considerando la baja inversión mencionada, propició la fundación de poblados de gran relevancia regional, como las actuales cabeceras de los departamentos jujeños homónimos, San José de la Rinconada y Santa Catalina, u otros pueblos como Antiguyoc, Ajedrez, Santo Domingo u Oratorio, los dos primeros hoy abandonados, y los segundos, retrasladados a localizaciones cercanas.

La explotación minera también implicó la edificación de instalaciones de distinta complejidad dedicadas a la extracción y procesamiento de los minerales de oro localizados en diversos sectores de la puna, muchas de las cuales perduran hasta hoy en el paisaje. En la Tabla 1 se enumeran las primeras referencias a estos asientos de mineral, yacimientos e instalaciones identificadas en los registros escritos. Los más importantes han sido señalados en un mapa del área (Figura 1).

Líneas atrás nos referimos a la construcción de ingenios de procesamiento de minerales en la región. Existen, asimismo, otro tipo de instalaciones mineras que, lejos de constituirse como poblado o de contar con el instru- mental específico de los ingenios, lograron reunir áreas de trabajo y unidades residenciales más o menos numerosas, dispersas en un mismo sector. Un ejemplo de ello es San Francisco, en la cuenca del río Santa Catalina, asiento de mineral desde el año 1657, cuando un indio descubridor encontró en este cerro una veta de oro que llamó de Las Ánimas (ABNB, Minas 62-4, año 1657). En un trayecto de $800 \mathrm{~m}$ a lo largo de la quebrada del río San Francisco, se observan evidencias de labores de extracción de oro en veta consistentes en 16 socavones y piques de diversas dimensiones y profundidades, al lado de uno de los cuales se registró una pequeña plataforma empedrada, como también desmontes y pozos producidos por la explotación aurífera aluvial y áreas de tratamiento del mineral (Angiorama y Becerra 2012). Diferente es el caso de muchas de las áreas de extracción y lavado de sedimento aurífero localizadas en la cuenca del sur de Pozuelos y también del río Santa Catalina, en las cercanías de cursos de agua temporarios de muy bajo caudal. Allí sólo se observan trincheras y pozos ${ }^{6}$ en áreas de unos $50 \mathrm{~m}$ de

6 Las trincheras, de no más de $3 \mathrm{~m}$ de profundidad, tienen un ancho de aproximadamente $2 \mathrm{~m}$ y algunas alcanzan los $50 \mathrm{~m}$ de longitud (Angiorama y Becerra 2012). 


\begin{tabular}{|c|c|}
\hline Asiento/Mina & Primeras menciones identificadas \\
\hline $\begin{array}{l}\text { Asiento de Mineral } \\
\text { de Cochinoca }\end{array}$ & $\begin{array}{l}\text { Año 1600: "en las minas de Cochinoca donde ahora de presente están en labor de las dichas minas que es en el asiento de Queta" (ATJ, Carpeta 1, Leg. } \\
\text { 16, año } 1600 \text {, fs. 11-11v). }\end{array}$ \\
\hline $\begin{array}{l}\text { Mineral de Oro de } \\
\text { Ajedrez }\end{array}$ & Año 1627: "mineral del Ajedrez" (ATJ, Carpeta 26, Leg. 794, año 1706, f. 1). \\
\hline $\begin{array}{l}\text { Nuestra Señora de } \\
\text { Guadalupe }\end{array}$ & Año 1627: "Minas de oro de Guadalupe" (ATJ, Carpeta 26, Leg. 794, Año 1706, f. 1). \\
\hline Pan de Azúcar & Año 1627: "un cerro que llaman del Pan de Azúcar mineral de plata" (ATJ, Carpeta 26, Leg. 794, año 1706, f. 1) \\
\hline $\begin{array}{l}\text { Ingenio de San Jo- } \\
\text { seph de Cochinoca }\end{array}$ & Año 1629. "ingenio de moler metales en la jurisdicción de esta ciudad" (ATJ, Carpeta 5, Leg. 86, f. 1). \\
\hline $\begin{array}{l}\text { San Bernardo del } \\
\text { Valle Rico del Oro o } \\
\text { Valle Rico }\end{array}$ & Año 1644: "al asiento de San Bernardo del Valle Rico que se registró ante mí en 2 de noviembre de 1644" (ABNB, Minas 62-3, año 1646, f. 9). \\
\hline $\begin{array}{l}\text { Ingenio de San } \\
\text { Isidro de Madrid }\end{array}$ & $\begin{array}{l}\text { Año 1646: "a donde voy a fundar un ingenio" (ABNB, Minas 62-3, año 1646, f. 24). } \\
\text { Año 1647-1648: "hacer una capilla en el ingenio de San Isidro de Madrid que está en el Valle Rico" (ABNB, EC No 25, año 1674, f. 116v). }\end{array}$ \\
\hline Cerro los Apóstoles & Año 1646: "descubridor del cerro de los Apostoles en el Valle Rico" (ABNB, Minas 62-3, año 1646, f. 21). \\
\hline $\begin{array}{l}\text { Santiago de la } \\
\text { Rinconada }\end{array}$ & $\begin{array}{l}\text { Año 1646: refiriéndose a años antes - sin decir cuántos- "se descubrió asimismo las minas de la Rinconada del mismo género las cuales se han ido } \\
\text { acabando y despoblándose" (ABNB, Minas 62-3, año 1646, f. 24). } \\
\text { Cambio de nombres: } \\
\text { Santiago el Mayor de la Rinconada (ABNB, Minas 62-3, año 1646, f. 30); Santiago de la Rinconada de Oro (ATJ, Carpeta 15, Leg. 403, año } \\
\text { 1666). } \\
\text { San Francisco de la Rinconada del Oro (ATJ, Carpeta 32, Leg. 1075, año 1733) } \\
\text { San Joseph de la Rinconada (ATJ. Carpeta 51, Leg. 1680, año 1777). } \\
\text { Año 1803: "se fundamentó y formalizó el asiento y pueblo que hoy se llama San José de la Rinconada, y en otro tiempo antiguo San Francisco del Valle del } \\
\text { Oro" (AGN, Sala IX, 23-5-6, año 1803, f. 82). }\end{array}$ \\
\hline Asiento de la Cruz & Año 1647: "asiento de la Cruz minas del Valle Rico jurisdicción de la ciudad de Salta" (ABNB, EC No25, año 1674, f.81; Albeck y Palomeque 2009) \\
\hline Coyahuayma & Año 1656: "y desde el dicho la deresera Coiaguaima” (ABHS, CMVT, año 1737, f. 1v). \\
\hline Cerro Granada & Año 1656: “y el cerro de la Granada” (ABHS, CMVT, año 1737, f. 1v). \\
\hline San Felipe & Año 1657: "el asiento de San Felipe a la veta de la Concepción que labró el capitán Pedro de Tapia Montalvo" (ABNB, Minas 62-4, año 1657, f. 13). \\
\hline San Francisco & $\begin{array}{l}\text { Año 1657: "asiento y mineral de oro de San Francisco", "que está el dicho cerro cosa de una legua o poco más del asiento de la Cruz" (ABNB, Minas } 62-4 \text {, } \\
\text { año } 1657, \text { f. 21, 13). }\end{array}$ \\
\hline Santa Catalina & Año 1657: Asiento de Santa Catalina (AHPJ, CMVT, Caja 2, Carpeta 105, año 1657). \\
\hline $\begin{array}{l}\text { Santiago de las } \\
\text { Ánimas }\end{array}$ & Año 1657: "descubridor de este Asiento de Santiago de las Ánimas y de otros en este Valle Rico" (AHPJ, CMVT, Caja 2, Carpeta 105, año 1657, f. 1). \\
\hline $\begin{array}{l}\text { Mineral San Joseph } \\
\text { del Oro }\end{array}$ & Año 1707: "la descubridora del nuevo mineral de oro nombrado de San Joseph en el río de los Uros" (ATJ, Carpeta 26, Leg. 806, año 1707, f. 2). \\
\hline Yaretaioc & Año 1718: “abra de Yaretaioc donde están unas minas" (ATJ, Caja 37, Leg. 1226, año 1751, f. 23). \\
\hline Santo Domingo & Año 1747: "trabajo de lavadero de oro que tenía en dicho paraje de Santo Domingo" (ATJ, Carpeta 36, Leg. 1200, año 1747, f. 1). \\
\hline Antiguioc & Año 1776: Hacienda de Nuestra Señora del Carmen de Antiguioc (ATJ, Carpeta 50, Leg. 1653, año 1776). \\
\hline Timón Cruz & Año 1789: Timón Cruz (AGN, Sala XIII, 17-2-1) \\
\hline
\end{tabular}

Tabla 1: Cronología de los asientos de mineral y yacimientos puneños según las primeras referencias encontradas en la documentación colonial.

diámetro -aunque algunas alcanzan los $100 \mathrm{o}$ incluso superan los $500 \mathrm{~m}$, asociadas a no más de tres estructuras habitacionales pequeñas, de probable residencia temporaria. En los quince casos registrados arqueológicamente se dificulta en gran medida la asignación cronológica de las evidencias detectadas (Angiorama y Becerra 2010; 2012). Los documentos nos permiten postular fechas aproximadas del posible inicio de algunos de los trabajos, aunque no puede descartarse tampoco que las evidencias observadas sean previas a estos registros o que se traten de labores efectuadas en el pasado reciente. 
Por otra parte, la explotación de los yacimientos de plata de la región también requirió la construcción de instalaciones dedicadas al procesamiento de los minerales. Éstas fueron más acotadas que las auríferas y estuvieron concentradas en el sur de la cuenca de Pozuelos e inmediaciones. Las minas de plomo, plata y zinc de Pan de Azúcar y Mina Chinchillas o Fundiciones, presentan evidencias de este tipo, como también áreas más alejadas de las fuentes de procedencia de los minerales argentíferos, tales como los sitios de Tabladitas, Chajarahuayco y el valle de Coyahuayma. Las mismas alcanzaron distintas escalas y características. En Fundiciones se ha registrado una instalación consistente en cuatro hornos de fundición con diverso estado de conservación, alineados a lo largo de un cauce de agua a metros del yacimiento mineral (Fundiciones 1) y un segundo complejo, a $2.5 \mathrm{~km}$ del anterior, con cinco estructuras de combustión, tres de ellas localizadas en un recinto posiblemente techado, dos unidades habitacionales adosadas y un refugio techado en falsa bóveda, también en la margen de un cauce de bajo caudal (Fundiciones 2) (Figura 2). Otra instalación de escala semejante se detectó en el valle de Coyahuayma, a ambas márgenes del río Rosario. En ella se han podido registrar evidencias de las primeras etapas de procesamiento del mineral, previo a la fundición. El complejo consta de dos sectores constructivos, complementarios entre sí. Uno de ellos presenta un conjunto de cinco marays, la base de un horno de fundición, dos plataformas empedradas, una de mayores dimensiones a la que llega un canal que debió conducir agua desde el río y también una estructura con tres vanos en arco con rocas colocadas en posición de canto (Figura 3). Esta última resulta semejante a los recintos registrados por Lechtman (1976) en Perú, en donde se realizaba la molienda de minerales mediante fuerza hidráulica. En el segundo sector, se observaron los restos de al menos tres hornos de fundición, alineados al pie de una ladera. Los otros tres sitios identificados en la región, a diferencia de éstos, consisten únicamente en la presencia de un horno de fundición, no asociado claramente a otras estructuras. Los mismos se localizan en una de las laderas del cerro Pan de Azúcar (Pan de Azúcar 26), en Tabladitas 1 y en Chajarahuayco 25. En este último caso, es posible que en la margen opuesta del cauce donde se encuentra la base del horno identificado, se ubique la base de otro, casi completamente destruido (Angiorama y Becerra 2010).

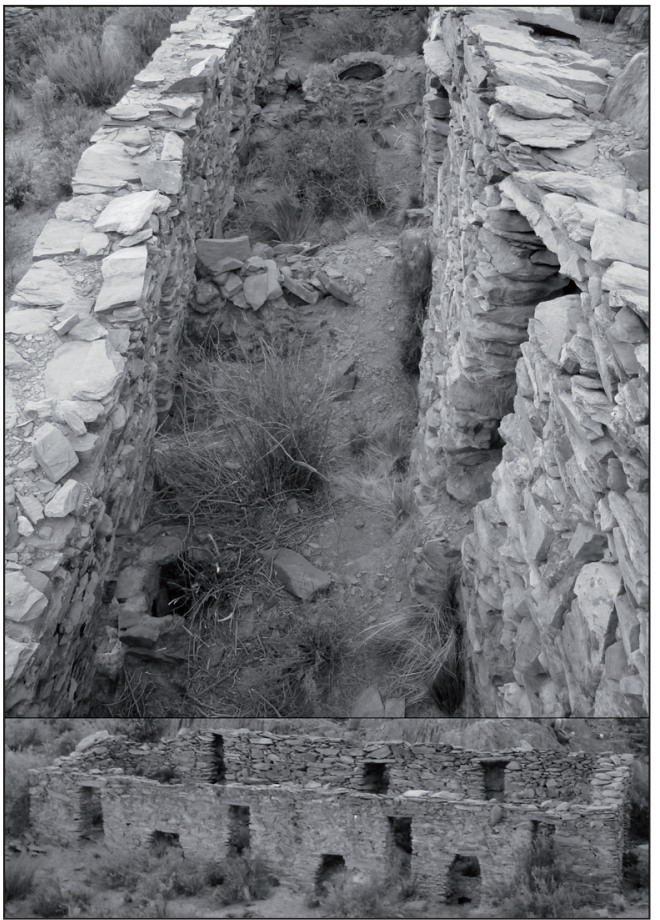

Figura 2: Vistas de un sector de la instalación de Fundiciones 2 donde se observan tres hornos de fundición de tipo reverbero en un recinto especialmente diseñado para albergarlos.

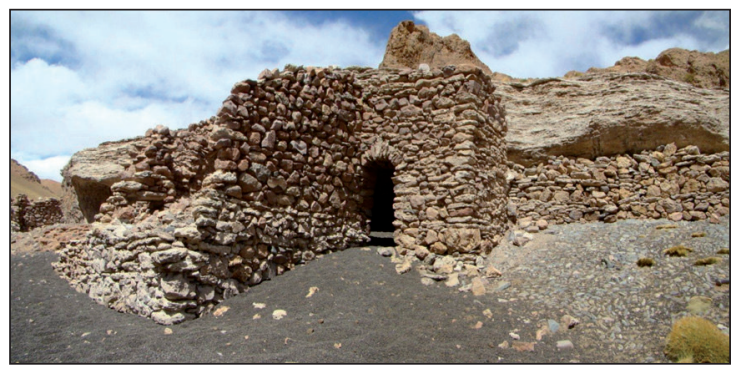

Figura 3: Vista de la estructura con vanos en arco presente en Casablanca, posiblemente construida como parte de un molino accionado por fuerza hidráulica.

Se debe destacar que, a pesar de que la documentación dé cuenta en 1629 de la presencia de un ingenio para procesar minerales de plata extraídos en las minas del cerro del Espíritu Santo a partir del beneficio por amalgamación de mercurio (ATJ, Carpeta 5, Leg. 86, año 1629, f. 1), o refiera a la posesión y aprovisionamiento de azogue por parte de mineros locales (ATJ, Carpeta 32, Leg. 1075, año 1733; ATJ, Carpeta 59, Leg. 1914, año 1789), las prospecciones 
intensivas realizadas en gran parte de las áreas con yacimientos argentíferos de la región de estudio, indican el empleo predominante del método por fundición (Angiorama y Becerra 2010, Becerra et al. 2014). Ya sea mediante un horno aislado como el de Pan de Azúcar 26, Tabladitas 1 y Chajarahuayco 25, o en cuatro o cinco como en las instalaciones a mayor escala de Casablanca y Fundiciones 1 y 2 , los beneficiadores puneños emplearon la metalurgia extractiva (y posiblemente la refinación) de minerales de plomo ricos en plata. Los análisis de escoria realizados indican que los procedimientos metalúrgicos llevados a cabo fueron considerablemente eficientes, habiendo alcanzado temperaturas y condiciones de oxidación suficientes en la mayoría de los casos (Becerra et al. 2014a). La tecnología elegida habría sido fundamentalmente la de hornos de reverbero, similares a los registrados en otras áreas andinas (p.e. Cohen et al. 2009; Téreygeol y Cruz 2012), tanto en su diseño como en su funcionamiento (Becerra 2014). Sólo la instalación de Casablanca podría haber incorporado también el beneficio por amalgamación de mercurio si atendemos al posible empleo de un ingenio hidráulico y a la existencia de plataformas empedradas, ausentes en el resto de los complejos de la región.

La preferencia de los mineros puneños por la fundición por sobre la amalgamación no sorprende si se analiza con cuidado el contexto en el que estas actividades tuvieron lugar. En palabras de José Tames, dueño de la mina San Francisco de Asís, en un área vecina a la puneña, la "distante provisión de azogues" resultaba una "traba terrible, que suspende con daño irreparable los progresos del mineral, porque demora el beneficio de los metales". Esto se debía a que no sólo "hoy está muy escaso" sino que "el recurrir por este ingrediente de absoluta necesidad a los reales almacenes de Potosí [...] ofrece mucha retardación, muchos gastos, y muchas mermas" (AGN, Sala IX, 36-2-5, año 1802, f. 3). Asimismo, las autoridades de la Intendencia de Gobernación de Salta entre 1789 y 1795 evaluaron a su vez la posibilidad de facilitar el acceso al tan requerido mercurio, reteniendo este mineral en la ciudad de Salta en su camino a Potosí. Sin embargo, según la investigación efectuada "en toda la comprensión de esta provincia no se necesita de aquel ingrediente hasta que tal vez con el tiempo se descubran minerales capaces de su consumo y que produzcan a Su Majestad y estos vasallos las ventajas que tanto apetece" (ABHS, Fondos de Gobierno, Carpeta 12A, año 1789, f. 7v).
Es sabido que la mayor ventaja comparativa del método de amalgamación por sobre la fundición fue la de procesar menas de baja y media calidad (Bakewell 2000:369). Por el contrario, sus dos grandes limitaciones fueron la dependencia de la oferta y provisión del azogue -monopolio de la corona y afectada a los propios vaivenes de cualquier producción mineral- como también las inversiones requeridas para edificar las instalaciones necesarias para su empleo. Molinos, buitrones, hornos, piletas y canales exigieron la compra de materiales, la búsqueda de trabajadores especializados en la nueva técnica, elevando en gran medida los costos. En este contexto, y situando a la puna de Jujuy como una región periférica de los grandes centros mineros, el empleo de la fundición, de menor inversión, sobre minerales ricos -aunque de yacimientos superficiales y de poco futuro, al decir de las autoridades- habría sido un buen equilibrio entre costos y beneficios. A esto se sumaría probablemente la posibilidad de escapar de los circuitos legales de registro y pago por la producción de plata obtenida.

Para finalizar, es importante señalar que, sin negar la relevancia de la minería en la ocupación europea del área y su organización territorial, tanto desde el análisis documental como del arqueológico, debe reconocerse que las instalaciones de trabajo minero-metalúrgico propiamente dicho no son comparables ni en escala ni en número a las conocidas para otras áreas mineras surandinas vecinas. Como describimos anteriormente, en toda la región tenemos referencias claras a la instalación de sólo tres ingenios en la primera mitad del siglo XVII, dos dedicados al tratamiento de minerales de oro y uno a los de plata, mientras que a finales del XVIII sabemos de una compañía con grandes inversiones que habría fundado al menos un ingenio, aunque poco conocemos de sus características (ATJ, Carpeta 59, Leg. 1914, año 1789). Ya sea por cuestiones de conservación como por localizarse en sectores aún no prospectados del área, ninguno de ellos ha podido ser aún identificado arqueológicamente ${ }^{7}$. Como mencionamos, únicamente se han registrado evidencias del empleo del método de fundición para el beneficio de

\footnotetext{
7 En el caso de la compañía minera llevada adelante por Ángel Antonio de la Barcena y Manuel Fernández de Baldivieso en 1789 , en base a las propiedades del primero en la región, podríamos sugerir, a modo de hipótesis, que las instalaciones de Fundiciones 1 y 2 y/o la de Casablanca podrían haberse enmarcado en esta inversión (Becerra 2014).
} 
los minerales y éstas consisten sólo en seis instalaciones asignables al período en estudio.

En cuanto a aquellas dedicadas a la extracción y procesamiento de oro, son más numerosas que las anteriores, aunque también presentan una baja escala de inversión en infraestructura. Es claro que la facilidad de acceso a los aluviones auríferos habría permitido una explotación eficaz sin grandes esfuerzos, aunque también lo es que mínimas inversiones en infraestructura habrían permitido alcanzar una rentabilidad mayor y más sostenida, tal como ocurrió en otras regiones en similares condiciones (Bargalló 1955; Cuadra y Arenas 2001). La cuestión, entonces, podría radicar más en quiénes y en qué circunstancias se dedicaron a estas tareas, y no tanto en las características de los minerales disponibles.

\section{* Tras un segundo Potosí}

Como ya hemos mencionado, quienes invirtieron en la minería de la puna en distintos momentos expresaron diversas alabanzas a las riquezas minerales de la región, dando cuenta de sus deseos de descubrirlas y explotarlas. Incluso mineros de otras áreas la visitaban, uno de los cuales hasta llegó a decir "que era más mucho que su Estarca si se seguía" (ABNB, Minas 62-4, año 1657, f. $45 \mathrm{v}$ ). Sin embargo, los diferentes emprendimientos llevados a cabo no alcanzaron ni de cerca el esplendor que sus mineros soñaron en un inicio. Ninguno de los asientos de mineral que fueron estableciéndose en la inmensidad puneña se convirtió en el tan ansiado segundo Potosí, como uno de los dueños de la hacienda de la Rinconada pretendía al estimular el asentamiento de mineros en el poblado homónimo, con el objetivo de que "creciera el pueblo como Potosi”" (AGN, Sala IX, 34-4-6, año 1803, f. 8). Los minerales de algunos yacimientos se extinguieron, inundaron, o simplemente, y por diversas razones, no fueron objeto de grandes y estables explotaciones, tales como las que sus promotores hubieran deseado. Las características de las evidencias registradas en el campo arriba descriptas son elocuentes de la falta de explotaciones comparables a las de los centros mineros andinos contemporáneos más reconocidos. Sin embargo, a pesar de los "fracasos" previos, a lo largo de todo el período colonial se observan nuevos intentos e inversiones para la realización o continuación de las explotaciones, siempre con la esperanza de finalmente llegar a convertirse en "el minero más rico que hubiera en el Perú" (AGN, Sala IX, 30-6-7, año 1800, f. 2).

En el caso de los mineros de origen español, sabemos que en las primeras décadas de la conquista de la región, aquéllos que fueron beneficiados con mercedes de tierras y/o encomienda en la puna o áreas cercanas, se involucraron en la explotación de las minas locales (Cfr. Sica 2006; Albeck y Palomeque 2009; Becerra 2014). También lo hicieron otros que, trasladándose o enviando en su nombre a socios o a sus trabajadores indígenas, se declararon descubridores de nuevas vetas allí y/o invirtieron en la construcción de instalaciones para el procesamiento de minerales (p.e., ABNB, Minas 62-3, año 1646; ABNB, Minas 62-4, año 1657). Más de un siglo después, mantuvieron esta iniciativa los hacendados, empresarios y arrendatarios localizados en los asientos de mineral puneños ${ }^{8}$. Éstos habrían sido los responsables de los distintos ingenios mencionados en la documentación y de las instalaciones de envergadura registradas arqueológicamente, como las de Casablanca, Fundiciones 1 y 2 , aunque también de algunos de los lavaderos de oro aluvial localizados en terrenos de su propiedad y trabajados de manera simultánea a otras actividades de la hacienda. Fue también destacada la actuación de las autoridades con injerencia en asuntos mineros, tales como los tenientes de gobernador y los subdelegados que, en el primer período y luego en el último cuarto del siglo XVIII, ejercieron sus funciones como alcaldes de minas. Desde esta posición resolvieron y generaron conflictos, colaboraron con algunos mineros en desmedro de otros, aprovecharon los huecos en la legislación a su beneficio y se convirtieron en piezas claves en el entramado desarrollado en torno a la minería local (Becerra y Estruch 2011).

Más allá de los problemas intrínsecos a la actividad y comunes a la mayoría de las áreas mineras andinas, como el agotamiento de las vetas, la creciente dificultad de acceso a las mismas, las inundaciones de los piques y socavones, entre otros, el análisis de los registros escritos nos permite observar que los mineros coloniales resaltaron especialmente la falta de mano de obra para sus emprendimientos,

\footnotetext{
8 Ver por ejemplo,ATJ, Carpeta 33, Leg. 1083, año 1733; ABHS, CMVT, año 1737; ATJ, Carpeta 50, Leg. 1653, año 1776; AGN, Sala IX, 33-8-5, año 1793; AGN, Sala IX, 34-4-6, año 1803.
} 
sin la cual no era posible la continuidad de los trabajos. ${ }^{9} \mathrm{~A}$ diferencia de lo que ocurrió en Potosí y en algunos distritos puntuales, muchas otras regiones mineras y entre ellas la puna de Jujuy, no contaron con un sistema de mita que proveyera regularmente de mano de obra a bajo costo para el impulso de las labores de los yacimientos y el beneficio de los minerales extraídos.

Nos preguntamos, entonces, cómo lograron los mineros de esta región reunir trabajadores para sus emprendimientos. Por un lado, observamos que algunos de los primeros proyectos mineros registrados contaron con los indios encomendados de la puna y de áreas aledañas como mano de obra (ATJ, Carpeta 1, Leg. 17, año 1602; Sánchez 2003; Sica 2006). Sin embargo, pronto los mineros solicitaron la concesión de mitayos para desarrollar distintas tareas vinculadas a la actividad. Es así que, aún en contra de las ordenanzas locales ${ }^{10}$ que sólo aceptaban el concierto voluntario de indios para este tipo de trabajos, parte de la mita de plaza exigida a los indios de la encomienda de Casabindo y Cochinoca -concedida primero a Salta y luego a Jujuy- fue desviada a las labores mineras locales de quienes como descubridores las requiriesen, aunque cedida en algunas ocasiones sólo en número limitado (ABNB, Minas 62-3, año 1646; Becerra 2014; Sica 2014). Este medio para la obtención de mano de obra no estuvo únicamente vigente en el siglo XVII, sino que se detecta también en los inicios del XIX, como una política de impulso al desarrollo minero de la Intendencia de Salta del Tucumán (AGN, Sala IX, 36-2-5, año 1802).

De esta manera, los mineros contaron con trabajadores no especializados, mientras que aquellos que estaban dedicados a tareas más complejas o que requerían mayor conocimiento y destreza, podrían ser trasladados

9 ATJ, Carpeta 8, Leg. 170, año 1639; ABNB, Minas 62-3, Año 1646; AGN, Sala XIII, Documentos Diversos, Sección Colonial, Leg. 11; AGN, Sala IX, 36-2-5, año 1802.

${ }^{10}$ La ordenanza 51 del Oidor Francisco de Alfaro de 1611 establecía que los indios "pueden ser compelidos sólo lo pueden ser para guardar ganados, hacer casas y edificios o servir en cosas manuales de casa porque a otra cosa no han de ser compelidos y en especial no lo han de ser a ir a minas". Sin embargo, la 54 declaraba que "los indios podrán de su voluntad concertarse para otros servicios como sea de su voluntad y en este caso no se les pone límite a lo que han de llevar por su trabajo" (Levillier 1918: 311-312). por los mismos empresarios desde Potosí (AGN, Sala IX, 36-2-5, año 1802, f. 10). Pero la contratación de indígenas para las labores mineras no se redujo a estas cesiones otorgadas por los capitulares de una u otra ciudad capital a quienes mantuvieran explotaciones en la puna. A partir de nuestra investigación, hemos observado que, a pesar de las quejas de los mineros y de las autoridades por la supuesta falta de indios disponibles para las tareas - por su poca destreza o disciplina al trabajo-, hay claras evidencias de que de modo independiente (a escala individual o familiar, aunque no se descarta el nivel comunal) o como contratados en emprendimientos de europeos, indígenas de distintas procedencias y condiciones participaron activamente de las prácticas extractivas y de beneficio de la región, tanto como expertos en fundición o cateo, como en calidad de mano de obra para tareas no especializadas ${ }^{11}$. Además de los indígenas encomendados de Casabindo y Cochinoca, empleados en las labores mineras en la puna y en otros yacimientos de Potosí, Lípez o Chichas (AGN, Sala XIII, Documentos Diversos, Sección Colonial, Leg. 11, f. 77; AHPJ, CMVT, Caja 8, Carpeta 256, año 1654; Madrazo 1982; Zanolli 1995), a mitad del siglo XVII se detecta la presencia de indígenas de origen desconocido, y que se habría contratado a mineros de otras regiones para catear y explotar en nombre suyo los yacimientos puneños (ABNB, Minas 62-4, año 1657). Asimismo, un siglo más tarde, funcionarios borbónicos empadronaron un gran número de indios forasteros, algunos de los cuales podrían haberse trasladado a la puna debido a la posibilidad de trabajo en emprendimientos mineros en ella o la búsqueda de yacimientos de modo independiente (Palomeque 1994; Gil Montero 2004; Becerra 2014).

Gran parte de la materialidad observada en terreno da cuenta de viviendas, lavaderos, trincheras e incluso hornos en parajes aislados como los de Tabladitas 1 y Chajarahuayco 25 ya mencionados, que podrían haber sido construidos, habitados o empleados por estos indígenas en sus tareas de extracción, aprovechamiento de des-

\footnotetext{
${ }^{11}$ AHPJ, CMVT, Caja 2, Carpeta 105, Año 1657; ABNB, Minas 624, Año 1657; ATJ, Carpeta 26, Leg. 806, Año 1707; ATJ, Carpeta 26, Leg. 815, Año 1708; ABHS, CMVT, Año 1737; ATJ, Carpeta 36, Leg. 1200, Año 1747; AGN, Sala IX, 30-5-2, Exp. 31, Leg. 35 , Año 1791.
} 
montes abandonados (juqueo), o beneficio de minerales a su propia costa. Asimismo, las instalaciones de mayor envergadura como las de Fundiciones y Casablanca habrían requerido de estos trabajadores para su funcionamiento.

Es necesario destacar que la facilidad de acceso al mineral les habría permitido a los indios mineros una libertad de acción -dentro de un contexto coercitivo como el colonial-, que iría en contra de los intereses de los mineros que necesitaban trabajadores estables para sus emprendimientos. Se registran quejas de estos últimos afirmando que, aunque supuestamente bien pagados y tratados, los indígenas preferían mantener sus tareas temporarias a contratarse a tiempo completo en una actividad más exigente, como la de la extracción en veta o las tareas de beneficio en una explotación española (véase AGN, Sala IX, 36-2-5, año 1802).

Esta minería a baja escala, que posiblemente continua más allá de los vaivenes de las explotaciones de mayor envergadura, habría sido una de las vías de acceso a la moneda de los indígenas encomendados y forasteros localizados en la puna. Algo impensado en otras regiones del Tucumán colonial que estaban fuera de la jurisdicción jujeña, pero a la vez necesario para el cumplimiento de las distintas obligaciones originadas a partir de la conquista: tributo, arriendos, pagos al clero, compra de bienes alóctonos, cumplimiento de deudas, etc. Esto se habría dado probablemente mediante el rescate del mineral extraído, transferido a las pulperías de la región o a otros intermediarios. Documentación de mediados del siglo XVII refiere a indígenas mineros en su búsqueda de obtención de metálico (ABNB, Minas 62-4, año 1657), prácticas que no serían exclusivas de este período, sino que tal como lo habían planteado ya Conti y Santamaría (1994) y Palomeque (1994), continuarían incluso a finales de la colonia ${ }^{12}$.

\footnotetext{
12 Estos investigadores plantean que, a finales del siglo XVIII, la población encomendada de la puna (originarios), más allá de sus participaciones puntuales en la actividad minera regional, habría obtenido metálico principalmentemediante la contratación de fletes hacia el Alto Perú y el resto del Tucumán, la producción de pólvora, y la extracción de sal (Palomeque 1994, 2000). En cambio, serían los forasteros de Rinconada y Santa Catalina quienes más se habrían dedicado a la actividad minera en este período, obteniendo de allí parte del metálico necesario para sus obligaciones (Conti y Santamaría 1994; Palomeque 1994, 2000).
}

La documentación analizada en pos de esta investigación nos permite afirmar, además, que la minería brindó un escenario propicio para una variedad de negocios en los que el oro o la plata extraídos se transferían rápidamente y de manera informal a terceros que se encontraban lejos de la dura práctica extractiva o de beneficio. En este contexto, se entiende que más de un siglo después, refiriéndose a las doctrinas de Rinconada y Santa Catalina, se planteara desde la Intendencia de Salta que éstas eran

"[...] de las más pobladas de todas las de la campaña de la provincia pero de indios tributarios, foráneos, originarios, y yanaconas con minerales de oro y plata en cuyo rescate emplean continuamente españoles, comerciantes llevando licores, coca y otros efectos de castilla y de la tierra con que hacen un continuado giro de comercio bien lucrativo" (AGN, Sala IX, 30-5-2, Exp. 31, Leg. 35, año 1791, fs. 8, 8v).

\section{* A modo de cierre: la minería de la puna DE JuJuY EN EL CONTEXTO DEL TuCumán COLONIAL}

Como es sabido, la minería es una actividad que indefectiblemente modifica el paisaje del área en la que se localizan los yacimientos trabajados, dejando marcas visibles a su paso. Con el inicio de las explotaciones coloniales, además de los cambios "físicos" vinculados a la apertura o continuación de socavones, pozos, trincheras, $\mathrm{u}$ otros -que en algunos casos adquirieron escalas de una envergadura muy superior a las conocidas hasta entonces-, se dieron modificaciones a niveles mucho más profundos, transformándose las relaciones establecidas entre humanos y no humanos, entre las poblaciones indígenas y las wak'as de los cerros mineros y las fuerzas del inframundo. Lógicas económicas, rituales notariales y normas novedosas, poblados y circuitos más o menos diferentes se impusieron y convivieron con tradiciones antiguas de prácticas minero-metalúrgicas, inseparables de la religión, de la política y de la organización territorial prehispánicas.

La apropiación europea de las riquezas minerales, y en ese proceso, del espacio y sus poblaciones se dio de manera semejante en todas las regiones mineras de los Andes del sur. Sin embargo, en cada una de ellas adquirió 
también particularidades propias que se hace necesario analizar con profundidad en cada caso. En este artículo nos propusimos, entonces, sintetizar los resultados alcanzados en nuestro análisis de las prácticas minerometalúrgicas desarrolladas en la puna de Jujuy, en pos de incentivar la reflexión acerca de los procesos observados en esta región y la comparación con el resto de la macroregión conformada por el Tucumán colonial.

En este contexto, la puna de Jujuy se constituye en una región periférica al estar lejos de la productividad alcanzada por los centros mineros de relevancia del actual altiplano boliviano y a la vez, dependiente económicamente de la demanda de los mismos. De hecho, como hemos brevemente analizado en este artículo, la proyección de esta región como un área minera no habría estado sustentada tanto en la efectiva productividad de las minas locales, como en las expectativas - no siempre reales- de quienes se dedicaron a explotarlas y en las estrategias de algunos habitantes para aprovechar los beneficios que esta condición de "mineral" conllevaba.

Sin dejar de lado estas contradicciones, no podemos dejar de afirmar, sin embargo, que aún sin espectaculares explotaciones e instalaciones acordes a las expectativas generadas en distintos momentos, de modo casi desapercibido, a mediana y baja escala, la minería se constituyó en una actividad sin la cual no puede entenderse la historia y dinámica de los pobladores de la puna de Jujuy y su territorio durante el período colonial. Contra una visión completamente negativa del desarrollo minero que instalaron estudiosos y viajeros del siglo XIX, afirmando que la riqueza metalífera puneña había sido desperdiciada ante la falta de inversiones y explotaciones a mayor escala, donde los mineros españoles y los indios locales no habrían estado a la altura de las circunstancias (cf. Andrews [1825] 1915), observamos que las explotaciones mineras en la puna de Jujuy mantuvieron una relativa continuidad en el tiempo y, sobre todo, una extensión en el espacio que las hace un caso distintivo dentro del territorio de lo que fue la Gobernación del Tucumán primero, y luego la Intendencia de Salta del Tucumán. Aunque existen otras áreas o yacimientos de gran fama en el Tucumán con los que los de la puna pueden ser comparados, por haberse dado en ellos algunos procesos similares (valles calchaquíes, Famatina,
Capillitas, etc. $)^{13}$, consideramos que la región de estudio se destaca por el número de asientos mineros distribuidos en su territorio, - a pesar de las oscilaciones en sus explotaciones-, y por su efectiva consolidación como una región minera en la larga duración, más allá de los conflictos desatados y con todas las reservas del caso ya analizadas. Las posibilidades que esta actividad abrió - directa o indirectamente- a sus habitantes españoles e indígenas no son un tema menor. Tampoco lo son las estrategias desarrolladas para superar los obstáculos comunes a este rubro como la necesidad de mano de obra a bajo costo, especialmente teniendo en cuenta que la puna no se encontraba incluida en los distritos beneficiados por la mita minera toledana. A pesar de estas dificultades y de su posición periférica, europeos de diversos orígenes se asentaron en los poblados mineros de la puna o circularon por ellos, probablemente aplicando en la región lo que habrían visto, aprendido y utilizado en otros centros mineros contemporáneos; como por ejemplo los hornos de reverbero registrados arqueológicamente, que podrían haber implicado ventajas comparativas con otros métodos de beneficio.

Pero hemos destacado también que no sólo se movilizaron hacia la puna europeos deseosos de encontrar y explotar nuevas vetas, o unos pocos indios a su cargo. Por una parte, detallamos ya que los indios originarios reducidos en los pueblos de Casabindo y Cochinoca fueron trasladados a distintos asientos mineros y por otra, mencionamos asimismo la importancia de los indígenas forasteros que habrían ejercido la minería de forma independiente o a jornal en la puna. Contarían ellos también con la experiencia minera aprendida en los centros más septentrionales, tal como plantea Gil Montero (2011,

\footnotetext{
13 Recientemente hemos comparado los procesos de conformación de jurisdicciones mineras y disputas por mano de obra desarrolladas en la puna de Jujuy y los valles calchaquíes mostrando las grandes similitudes entre uno y otro a pesar de las particularidades regionales (Estruch et al. 2011). También los estudios sobre el mineral de Incahuasi, aunque dependiente del Corregimiento de Atacama, muestran el desarrollo de procesos semejantes a los observados en la puna de Jujuy (Lema 2012). Sólo el avance de investigaciones interdisciplinarias en cada una de estas áreas permitirá a su vez profundizar las comparaciones y confirmar o atenuar la aparente singularidad de ciertas características de la región puneña. El Grupo de Investigación sobre Minería en el Noroeste Argentino GEMINOA (UBA-UNT) actualmente se encuentra enfocado en esta tarea (Becerra et al. 2014b).
} 
2013) para el caso de los forasteros de San Antonio del Nuevo Mundo. De este modo, harían circular con ellos las nuevas ideas, innovaciones y tecnologías que iban desarrollando y aplicando de acuerdo a los requerimientos de los yacimientos y minas a explotar, los recursos disponibles y las destrezas propias. La existencia de una dinámica de circulación pendular o cíclica entre comunidades de origen y yacimientos en auge que se ha observado en estas áreas de los actuales territorios de Bolivia y Chile (González Casasnovas 2000; Gil Montero 2011), de donde precisamente provendrían parte de los indios forasteros registrados en nuestra región de estudio, no deja de ser sugerente para pensar la inclusión de ésta en esos grandes circuitos o el desarrollo de prácticas semejantes a nivel local.

En esta línea, y para finalizar, consideramos importante retomar lo que hace ya casi veinte años, Zanolli y Lorandi (1995: 102) plantearon para Jujuy (especialmente la región de quebrada y puna en los siglos XVI y XVII), afirmando que este espacio "era y no era el Tucumán. Compartía sus fronteras y compartía jurisdiccionalmente sus instituciones, pero su historia miraba hacia el septentrión, hacia Charcas".

El estudio en profundidad de las características de la minería puneña nos permite seguir sosteniendo esta posición particular, intermedia, de esta región en el espacio macroregional, especialmente si consideramos las dinámicas de circulación de personas y acceso de recursos observadas a la luz de la actividad extractiva en el área que brevemente describimos en este trabajo.

Agradecimientos Esta investigación fue realizada con becas y subsidios provenientes de CONICET y FONCyT. Agradezco especialmente a mis directores de beca y tesis, Carlos Angiorama, Estela Noli, Nicolás Nieva y Beatriz Ventura, y a mi consejero de estudios, Luis González. Asimismo a Lorena Rodríguez y Dolores Estruch. También a quienes en el campo, los archivos y bibliotecas me han recibido y ayudado tanto a lo largo de estos años, y a los evaluadores anónimos, cuyos comentarios me han permitido mejorar la primera versión de este trabajo. Ninguno de ellos, sin embargo, es responsable de lo aquí expuesto.

\section{* Referencias citadas}

\section{Fuentes documentales:}

I. Archivo y Biblioteca Nacional de Bolivia (ABNB)

Expedientes Coloniales (EC):

$\mathrm{N}^{\circ} 25$, año 1674. "El arzobispado de Charcas y el obispado de Tucumán sobre los linderos para la percepción de los diezmos de La Quiaca, Yavi, Aycate, Tapona y otros".

\section{Minas:}

Vol. 62, n 3, año 1646. "Relativo a las minas de oro de Santiago de la Rinconada y el cerro de los Apóstoles".

Vol. 62, n 4, año 1657. "Pleito sobre mina San Francisco de las Ánimas, en el Valle Rico”.

Vol. 62, n 7, año 1692-1712. "Pleito entre el Cabildo de Jujuy y Juan José Campero".

\section{Archivo General de la Nación, Argentina (AGN)}

Sala IX:

5-8-1, años 1784-1809, Jujuy. "Intendencia de Salta, Catamarca, varios".

30-5-2, año 1792. "Pulperías en los pueblos de la Puna".
30-6-7, año 1800. "Alcaldía de minas en la Rinconada".

33-8-5, año 1793. "Sumario contra subdelegado de la puna, J. Villegas".

23-5-6, año 1803. "Rinconada: procedimientos de A. Barcena con los mineros del pueblo".

34-4-6, año 1803. "Juicio cobro de arriendos en Rinconada".

36-2-5, año 1802. "Visita al mineral de San Francisco".

Sala XIII:

Documentos Diversos, Sección Colonial, Leg. 11, Casabindo y Cochinoca.

III. Archivo de Tribunales de Jujuy (ATJ)

Carpeta 1, leg. 17, año 1602. "Carta de poder y escritura de donación a Sanabria".

Carpeta 5, leg. 86, año 1629. "Compañía para trabajar minas en Cochinoca".

Carpeta 32, leg. 1075, año 1733. "Pleito por bienes de Petronila de Cañizares".

Carpeta 59, leg. 1914, año 1789 "Compañía minera Barcena-Baldivieso". 
IV. Archivo Histórico Provincial de Jujuy (AHPJ)

Colección del Marquesado del Valle de Tojo (CMVT):

Caja 2, carpeta 105, año 1657. "Provisión de Amparo de posesión de minas".

Caja 8, carpeta 256, año 1654. "Provisión a efecto de domesticar los pueblos de indios de casabindo y cochinoca y pagar tributos".

V. Archivo y Biblioteca Histórico de Salta (ABHS)

Colección del Marquesado del Valle de Tojo (CMVT):

Año 1737. Escribanías Públicas. "Estancia Peñas Blancas".

Fondos de Gobierno:

Caja 12A, año 1789. "Solicitud de N. Severo de Isasmendi de 400 libras de azogue".

Caja 14A, año 1793. "Expediente referente a que los pueblos de indios de la Puna no deben pagar derecho de composición".

\section{Publicaciones}

ALBECK, M. E. y S. PALOMEQUE. 2009. Ocupación española de las tierras indígenas de la puna y "raya del Tucumán" durante el temprano período colonial. Memoria Americana 17 (2): $173-212$.

ANDREWS, J. 1915 [1825]. Las provincias del norte en 1825. Universidad Nacional de Tucumán, Buenos Aires.

ANGIORAMA, C. 2011. La ocupación del espacio en el sur de Pozuelos (Jujuy, Argentina) durante tiempos prehispánicos y coloniales. Estudios Sociales del NOA 11: 125-142.

ANGIORAMA, C. y M. F. BECERRA. 2010. Evidencias antiguas de minería y metalurgia en Pozuelos, Santo Domingo y Coyahuayma (Puna de Jujuy, Argentina). Boletín del Museo Chileno de Arte Precolombino 15(1): 81-104.

2012. El oro de la puna: lavaderos, socavones y mineros en el período colonial. Arqueología de la minería aurífera del extremo norte de la Puna de Jujuy (Argentina). Revista Vestigios, Revista Latino-Americana de Arqueología Histórica 6(1): 50-80.

ASSADOURIAN, C. S. 1982. El sistema de la economía colonial. Mercado interno, regiones y espacio económico. Instituto de Estudios Peruanos, Lima.

BAKEWELL, P. 1989. Mineros de la montaña roja. Alianza, Madrid.

2000. La transferencia de la tecnología y la minería hispanoamericana, siglos XVI y XVII: algunas observaciones. En Hombres, Técnica, Plata. Minería y Sociedad en Europa y América, siglos
XVI-XIX, J. Sánchez Gómez y G. Mira Delli-Zotti (Comps.), pp. 363-375. Aconcagua Libros, La Otra América, Sevilla.

BARGALLÓ, M. 1955. La minería y la metalurgia en la América Española durante la época colonial. FCE, México.

BECERRA, M. F. 2009. Prácticas minero-metalúrgicas durante el Período Colonial: El complejo Fundiciones 1 como caso de estudio (actual Fundiciones, Departamento de Rinconada, Jujuy, Argentina). Tesis de Grado, Facultad de Ciencias Naturales, Universidad Nacional de Tucumán, Tucumán.

2012. Minería, población, paisajes y territorios: el caso de la Puna de Jujuy durante el período colonial (siglos XVII y XVIII). En Espacialidades altoandinas. Avances de investigación desde el Noroeste Argentino, A. Benedetti y J. Tomasi (Eds.). Editorial de la Facultad de Filosofía y Letras, Universidad de Buenos Aires. En prensa.

2014. "Para labrar y poblar" Prácticas minero-metalúrgicas en la Puna de Jujuy durante el período colonial (siglos XVII y XVIII). Tesis Doctoral, Facultad de Filosofía y Letras, Universidad de Buenos Aires.

BECERRA, M. F., C. I. ANGIORAMA y N. NIEVA. 2014. Hornos, minerales y escorias: una aproximación a la metalurgia extractiva en la Puna de Jujuy en época prehispánica y colonial. Revista Arqueología 20(1): 13-29.

BECERRA, M. F. y D. ESTRUCH. 2011. Alcaldes de minas, capitulares, cateadores y mineros. Una reflexión sobre las administración de la justicia en las causas mineras de la Puna de Jujuy (Siglos XVII y XVIII). Revista Historia del Derecho 42: 1-21.

2012. La minería colonial en la Puna de Jujuy a través de los documentos: sus prácticas y materialidades. En Actas del VCongreso Nacional de Arqueología Histórica, E. M. Rodríguez Leirado y D. Schávelzon (Eds.), Tomo 1, pp. 159-186. Editorial Académica Española, Saarbrücken.

BECERRA, M. F., D. ESTRUCH, L. RODRÍGUEZ, M. SNEIDER BARTOLUCCI y M. V. STARICCO. 2014b. "Esperanzados de resarcir los quebrantos y de aumentar sus intereses": emprendimientos mineros en el Antiguo Tucumán durante los siglos XVII hasta mediados del XIX. Ms en poder de la autora.

BOUYSSE-CASSAGNE, T. 2005. Las minas del centro-sur andino, los cultos prehispánicos y los cultos cristianos. Boletín IFEA $34(3): 443-462$

COHEN, C., T. REHREN y M. VAN BUREN. 2009. An archaeometallurgical study of the use of European furnaces in colonial Bolivia. Archaeometallurgy in Europe II, pp. 529-540. 
COIRA, B., P. CAFFE, A. RAMÍREZ, W. CHAYLE, A. DÍAZ, S. ROSAS, A. PÉREZ, B. PÉREZ, O. OROZCO y M. MARTÍNEZ. 2004. Hoja Geológica 2366-I/2166-III, Mina Pirquitas, Boletín 269. SEGEMAR, Buenos Aires.

COLE, J. 1985. The Potosí Mita, 1573-1700. Compulsory Indian Labor in the Andes. Stanford University Press, Stanford.

CONTI, V. 2010. Las actividades económicas. Jujuy en los circuitos económicos coloniales. En Jujuy de la Revolución a nuestros días. 1810-1910-2010, M. Lagos y V. Conti (Comps.), pp. 41-83. Editorial Universidad Nacional de Jujuy, Jujuy.

CONTI, V. y D. SANTAMARÍA. 1994. Mecanismos de intercambio en períodos de transición: el caso de los arrendamientos de dos estancias de la puna jujeña (1813-1819). Anuario de Estudios Americanos 51 (1): 123-142.

CORRÊA, R. L. 1995. Espaço, um conceito-chave da geografía. En Geografia: Conceitos e Temas, I. Elias de Castro, P. C. da Costa Gomes y R. Lobato Corrêa (Orgs.), pp. 15-47. Bertrand, Rio de Janeiro.

CRUZ, P. 2013. La piedra herida. Reflexiones metodológicas en torno de un establecimiento minero del altiplano surandino. En Los estudios andinos hoy. Práctica intelectual y estrategias de investigación, C. Zanolli, J. Costilla, D. Estruch yA. Ramos (Comps.), pp. 55-78. Prohistoria Ediciones, Rosario.

CRUZ, P., A. NIELSEN, F. TÉREYGEOL, J. P. DEROIN e I. GUILLOT. 2012. "La Pacificación del mineral". Cerro Lípez, un enclave minero en la contienda sobre el Nuevo Mundo. Vestigios, Revista Latino-Americana de Arqueologia Histórica 6(1): $11-44$.

CUADRA, W. y M. ARENAS. 20o1. El Oro de Chile. Tomo I. LOM Ediciones, Santiago.

ESTRUCH, D. 2013. Administración de la justicia y conflictos jurisdiccionales en el Jujuy colonial (siglos XVI y XVII). En El ocaso del imperio. Sociedad y cultura en el centro-sur andino, A. M. Lorandi (Comp.), pp. 125-152. Antropofagia, Buenos Aires.

ESTRUCH, D., L. RODRÍGUEZ y M. F. BECERRA. 2011. Jurisdicciones mineras en tensión. El impacto de la minería en el Valle de Yocavil y la Puna Jujeña durante el período colonial. Revista Histórica 35 (2): 69-100.

GAVIRA, M. C. 2005. Historia de una crisis: la minería en Oruro a fines del período colonial. Instituto Francés de Estudios Andinos, Universidad Mayor de San Andrés.
2008. Población indígena, sublevación y minería en Carangas. La Caja Real de Carangas y el mineral de Huantajaya, 1750-1804. Instituto Francés de Estudios Andinos, Centro de Investigaciones del Hombre en el Desierto, Arica.

GIL MONTERO, R. 2004. Caravaneros y transhumantes en los Andes meridionales. Población y familia indígena en la puna de Jujuy. 17701870. Instituto de Estudios Peruanos, Lima.

2011. Los pastores frente a la minería colonial temprana: Lípez en el siglo XVII. En En ruta: arqueología, historia y etnografía del tráfico sur andino, L. Núñez y A. Nielsen (Eds.), pp. 285-311. Encuentro Grupo Editor, Córdoba.

2012. San Antonio del Nuevo Mundo y las ciudades efímeras creadas por la minería de plata en los Andes coloniales. Ciencia Hoy 22: 40-48.

2013. Mecanismos de reclutamiento indígena en la minería de plata. Lípez (sur de la actual Bolivia), siglo XVII. América Latina en la Historia Económica 21(1): 5-30.

GLUZMAN, G. 2007. Minería y metalúrgica en la antigua gobernación del Tucumán (siglos XVI y XVII). Memoria Americana 15: $157-184$.

GONZÁLEZ, L. 1999. Arqueología y etnohistoria: evidencias de actividades minero metalúrgicas coloniales en el sur del valle de Santa María (Pcia. de Catamarca). Actas XV Congreso Nacional de Arqueología Chilena, Tomo I, pp. 29-47, Copiapó.

GONZÁLEZ CASASNOVAS, I. 2000. Las dudas de la Corona. La Politica de repartimientos para la minería de Potosí (1680-1732). Centro de Estudios Históricos, Madrid.

HABER, A. y C. LEMA. 2006. Dime cómo escribes y te diré quién eres. Textualizaciones del campesinado indígena de la Puna de Atacama. Memoria Americana 14: 119-137.

LECHTMAN, H. 1976. A Metallurgical Site Survey in the Peruvian Andes. Journal of Field Archaeology 3 (1): 1-42.

LEMA, C. 2012. Paisaje minero y producción aurífera colonial en el Mineral de Incahuasi (Catamarca, Argentina). En Actas del $V$ Congreso Nacional de Arqueología Histórica, E. M. Rodríguez Leirado y D. Schávelzon (Eds.), Tomo 1, pp. 261-279. Editorial Académica Española, Saarbrücken.

LEVILLIER, R. 1918. Correspondencia de la ciudad de Buenos Aires con los reyes de España 1615-1635, Tomo II. Biblioteca del Congreso Argentino, Madrid. 
MADRAZO, G. 1982. Hacienda y encomienda en los Andes. La Puna argentina bajo el marquesado de Tojo. Siglos XVII a XIX. Fondo Editorial, Buenos Aires.

PALOMEQUE, S. 1994. Intercambios mercantiles y participación indígena en la "Puna de Jujuy" a fines del Período Colonial.Andes 6:13-49.

2000. Acceso a los recursos y participación mercantil en una zona rural surandina (Puna de Jujuy, siglos XVIII y XIX). En Mercados Indígenas en México y los Andes, Siglos XVIII y XIX. J. Silva y A. Escobar (Coords.), pp. 177-210. Instituto Mora y CIESAS, México.

2006. La Historia de los señores étnicos de Casabindo y Cochinoca (1540-1662). Andes 17: 139-194.

PAZ, G. 2004. La hora del Cabildo: Jujuy y su defensa de los derechos del "pueblo" en 1811. En Revolución, política e ideas en el Río de la Plata durante la década de 1810. F. Herrero (Comp.), pp. 149-165. Ediciones Cooperativas, Buenos Aires.

PLATT, T., T. BOUYSSE-CASSAGNE y O. HARRIS. 2006. Qaraqara-Charka. Mallku, Inka y Rey en la Provincia de Charcas (siglos $X V$-XVII). Historia antropológica de una confederación aymara. Instituto Francés de Estudios Andinos, Plural editores, University of St. Andrews, University of London, Interamerican Foundation, Fundación Cultural del Banco Central de Bolivia, La Paz.

SAIGNES, T. 1987. Ayllus, mercado y coacción colonial: el reto de las migraciones internas en Charcas (siglos XVII). En La Participación indígena en los mercados surandinos. Estrategias y reproducción social. Siglos XVI a XX. O. Harris, B. Larson y E. Tandeter (Comps.), pp. 111-157. Centro de Estudios de la Realidad Económica y Social, La Paz.

SALAZAR-SOLER, C. 1997. Las Huacas y el conocimiento científico en el siglo XVI: a propósito del descubrimiento de las minas de Potosí. En Saberes y memorias en los Andes. In Memoriam Thierry Saignes, T. Bouysse-Cassagne (Ed. y Comp.), pp. 237-258. Institut des Hautes Etudes de l'Amérique Latine, Instituto Francés de Estudios Andinos, París-Lima.

2002. Innovaciones técnicas, mestizajes y formas de trabajo en Potosí de los siglos XVI y XVII. En O trabalho mestiço: manei- ras de pensar e formas de viver-séculos XVI a XIX, E. França Paiva y C. Anastasia (Orgs.), pp. 141-163. PPGH/UFMG, Annablume, São Paulo.

SÁNCHEZ, S. 2003. Un viaje entre la historia y la memoria: los 'ossa' jujeños. Anuario de Estudios Americanos 60: 41-76.

SÁNCHEZ ALBORNOZ, N. 1978. Indios y tributos en el Alto Perú. Instituto de Estudios Peruanos, Lima.

SICA, G. 2006. Del Pukara al Pueblo de Indios. El proceso de construcción de la sociedad indigena colonial en Jujuy, Argentina, siglo XVII. Tesis Doctoral, Universidad de Sevilla.

2014. Las otras mitas. Aproximaciones al estudio de la mita de plaza en la jurisdicción de Jujuy, gobernación de Tucumán, siglo XVII. Anuario de Estudios Americanos, 71 (1): 201-226.

TANDETER, E. 1992. Coacción y Mercado. La minería de la plata en el Potosí colonial 1692-1826. Editorial Sudamericana, Buenos Aires.

TÉREYGEOL, F. y C. CASTRO. 2008. La metalurgia prehispánica de la plata en Potosí. En Mina y metalurgia en los Andes del Surdesde la época prehispánica hasta el siglo XVII, P. Cruz y J. J. Vacher (Eds.), pp. 11-28. Institut de Recherche pour le Développement, Instituto Francés de Estudios Andinos, Sucre.

TÉREYGEOL, F. y P. CRUZ. 2012. Die Silberbergwerke von Potosi: Das wichtigste Technologiezentrum Südamerikas aus del Sicht der Autoren del Inka und der Spanier. DerAnschnitt 64 (2-3): 93108.

VAN BUREN, M. y C. COHEN. 2010. Technological changes in silver production after the Spanish conquest in Porco, Bolivia. Boletín del Museo Chileno de Arte Precolombino 15 (2): 29-46.

ZANOLLI, C. 1995. Omaguaca: la tierra y su gente. Presencia chicha hacia el sur de Talina. Siglo XVI. En Espacio, Etnías, Frontera. Atenuaciones políticas en el Sur del Tawantinsuyu, siglos XV-XVIII, A. M. Presta (Ed. y Comp.), pp. 319-339. Ediciones ASUR, Sucre.

ZANOLLI, C. y A.M. LORANDI. 1995. Tributo y servicio personal en el Tucumán Colonial. Memoria Americana 4: 91-104. 